\title{
Sex composition of living children in a matrilineal inheritance system and its association with pregnancy intendedness and postpartum family planning intentions in rural Ghana
}

Sebastian Eliason ${ }^{1 *}$, Frank Baiden², Derek Anamaale Tuoyire ${ }^{3}$ and Kofi Awusabo-Asare ${ }^{4}$

\begin{abstract}
Background: Sex composition of living children within the context of "sex preference" and its association with various reproductive health outcomes has been extensively studied in South and South East Asia. Although sex preference has been observed in sub-Saharan Africa, there is paucity of research on sex composition of living children and its association with reproductive health behaviours and outcomes, particularly in a matrilineal inheritance system. The purpose of the study was to explore the existence of sex preference in a matrilineal inheritance system. Specifically, the study sought to better understand the issues by examining the sex composition of living children and how it is associated with reproductive outcomes such as pregnancy intendedness and intention to use postpartum family planning among women in a matrilineal area of Ghana.
\end{abstract}

Methods: This was a cross sectional study conducted at four selected health facilities in the Mfantseman municipality of the Central Region of Ghana. Out of the 1914 pregnant women attending antenatal clinic selected using total enumeration, from 2nd January to 30th April 2012, 1091 with living children and complete socio-demographic data were recruited for this study. Descriptive, chi square and multivariate logistic regression analyses were conducted.

\footnotetext{
* Correspondence: sakeliason@yahoo.co.uk

1 Department of Community Medicine, University of Cape Coast, Cape Coast, Ghana

Full list of author information is available at the end of the article
}

(c) The Author(s). 2018 Open Access This article is distributed under the terms of the Creative Commons Attribution 4.0 International License (http://creativecommons.org/licenses/by/4.0/), which permits unrestricted use, distribution, and reproduction in any medium, provided you give appropriate credit to the original author(s) and the source, provide a link to the Creative Commons license, and indicate if changes were made. The Creative Commons Public Domain Dedication waiver (http://creativecommons.org/publicdomain/zero/1.0/) applies to the data made available in this article, unless otherwise stated. 
(Continued from previous page)

Results: The mean age of the 1091 respondents in this study was $28.2 \pm 6.0$ years with mean gestational age of $26.7 \pm$ 6.6 weeks. Whilst 78\% of the women had at least a son, $71 \%$ had at least a daughter, with those having only sons exceeding those with only daughters by 6.3\%. Also, majority of the women with more sons than daughters did not intend their current pregnancies. These observations, coupled with a sex ratio of 109 males to 100 females, inferred the existence of son preference. The levels of unintended pregnancy and intention to use postpartum family planning were high (70\% and 78\% respectively). There was an association between sex composition of living children and unintended pregnancy but no association between sex composition of living children and intention to use postpartum family planning. Women with only sons were $50 \%$ less likely to have unintended pregnancies compared to those with equal number of sons and daughters [AOR 0.5, 95\% Cl (0.3-0.8)]. Similarly, women over 30 years were $80 \%$ less likely to have unintended pregnancies compared to those $15-19$ years [AOR $0.2,95 \% \mathrm{Cl}(0.1-0.6)$ ]. The women with parity of 5 or more and resident in Anomabo were more likely to have unintended pregnancy compared to those with parity of up to two [AOR 3.8, 95\% Cl (1.7-8.59)] and those resident in Saltpond [AOR 1.8, 95\%Cl (1.1-2.8), respectively. In addition, the women resident in Anomabo were more likely to have intention to use postpartum family planning compared to those in Saltpond [AOR 1.8, 95\% Cl (1.0-3.3)].

Conclusion: There was persistence of more sons than daughters born in a predominantly matrilineal inheritance system and sex composition of living children had significant association with pregnancy intendedness but not with intention to use postpartum family planning.

Keywords: Sex composition, Unintended pregnancy, Postpartum family planning intention,

\section{Plain English summary}

Sex composition of living children within the context of "sex preference" and its association with various reproductive health outcomes has been extensively studied in South and South East Asia. Although sex preference has been observed in sub-Saharan Africa, there is paucity of research on sex composition of living children and its association with reproductive health behaviours and outcomes, particularly in a matrilineal inheritance system. The purpose of the study was to explore the existence of sex preference in a matrilineal inheritance system. Specifically, the study sought to better understand the issues by examining the sex composition of living children and how it is associated with reproductive outcomes such as pregnancy intendedness and intention to use postpartum family planning.

This was a cross sectional study conducted at four selected health facilities in the Mfantseman Municipality of the Central Region of Ghana. Out of the 1914 pregnant women attending antenatal clinic selected using total enumeration, from 2nd January to 30th April 2012, 1091 with living children and complete socio-demographic data were recruited for this study. Descriptive, chi square and multivariate logistic regression analyses were conducted.

The mean age of the 1091 respondents in this study was $28.2 \pm 6.0$ years with mean gestational age of $26.7 \pm$ 6.6 weeks. Whilst $78 \%$ of the women had at least a son, $71 \%$ had at least a daughter, with those having only sons exceeding those with only daughters by $6.3 \%$. Also, majority of the women with more sons than daughters did not intend their current pregnancies. These observations, coupled with a sex ratio of 109 males to 100 females, inferred the existence of son preference. The levels of unintended pregnancy and intention to use postpartum family planning were high (70\% and $78 \%$ respectively). There was an association between sex composition of living children and unintended pregnancy but no association between sex composition of living children and intention to use postpartum family planning. Women with only sons were $50 \%$ less likely of having unintended pregnancies compared to those with equal number of sons and daughters [AOR 0.5, 95\% CI (0.3-0.8)]. Similarly, women over 30 years were $80 \%$ less likely to have unintended pregnancies compared to those 15-19 years [AOR 0.2, $95 \%$ CI $(0.1-0.66)]$. The women with parity of 5 or more and resident in Anomabo were more likely to have unintended pregnancy compared to those with parity of up to two [AOR 3.8, 95\% CI (1.7-8.6)] and those resident in Saltpond [AOR 1.8, 95\%CI (1.1-2.8) respectively. In addition, women resident in Anomabo were more likely to have intention to use postpartum family planning compared to those in Saltpond [AOR 1.8, 95\% CI (1.0-3.3)].

In conclusion, there was persistence of more sons than daughters born in a predominantly matrilineal inheritance system and sex composition of living children had significant association with pregnancy intendedness but not with intention to use postpartum family planning.

\section{Background}

Sex composition of living children and its association with various reproductive health outcomes within the context of preference for one sex or the other, has been extensively studied in South and South East Asia, where an estimated 30-70 million women are believed to be 
unaccounted for [1], and sex ratios at birth as high as 130 males to 100 females have been observed [2]. Among the reasons identified to account for the situation are: the patriarchal nature of the society; the attitude that sons are more important and valuable than daughters in carrying out important religious roles; that sons have the right to inherit land; that sons support aged parents and perpetuate the family name [3].

According to a joint statement issued by five United Nations (UN) organizations including the Human Rights Office (OHCHR) in 2011, there is huge pressure on women to produce sons, which not only directly affects women's sexual and reproductive lives with implications for their health and survival, but also puts women in a position where they must perpetuate the lower status of girls through son preference [2].

A study by Chaudhuri found that in India, women with more sons than daughters were less likely to progress to higher parities than were women with more daughters than sons [4]. Other studies in South East Asia have shown that women with more sons are more likely not to want any more children and more likely to use modern family planning methods $[5,6]$.

In sub-Saharan Africa, balance has been observed as the most common type of preference. Of 28 sub-Saharan African countries reviewed in a study by Fuse, balance was found to be the most popular preference in 24 countries [7]. The study further revealed that though son preference is observed in every sub-region within sub-Saharan Africa, it appeared to be particularly prevalent in West Africa, especially Mali, Senegal and Burkina Faso. Daughter preferences have also been observed in some West African countries including Ghana, Liberia and Sierra Leone [7]. In Nigeria, a study showed that parental gender preferences did influence fertility behaviour and was largely shaped by social institutions [8].

In the studies cited above, one of the identified factors influencing son preference in sub-Saharan Africa is the patriarchal nature of society. However, there are very few studies on sex preference in matrilineal societies. One of the questions then is whether there will be preference for one sex or the other in matrilineal areas.

In the southern sector of Ghana where most of the Akans live [9], three main types of kinship systems exist: matrilineal, patrilineal and dual [10-12]. The matrilineal Akans trace their lineage through the female. Although matrilineal, it has elements of patriarchal structures. For instance, in most cases, the heads of matriclans are males. The other two major groups in the southern sector of the country, the Ewe and Ga-Adangbe, are patrilineal and patriarchal [12].

Under the matrilineal system, the relations consist of uterine siblings (i.e those born of the same mother but not necessarily the same fathers) [12]. It will be expected that in such a matrilineal system, there will be preference for daughters who will contribute to the matriclan or for balance, to ensure continuity. As noted by Fuse, the pattern for Ghana was for balance (47\%), daughter preference (21\%) and son preference (19\%) [7]; this was based on national data and did not consider these differences in lineage systems. A commonly used approach to studying sex preference investigates the association between family sex composition and actual fertility behaviours, such as family planning use or fertility desire [3]. The purpose of this study was to explore the existence of sex preference in a matrilineal inheritance system. Specifically, the study sought to better understand the issues by examining the sex composition of living children and how it is associated with reproductive or fertility outcomes such as pregnancy intendedness and postpartum family planning intentions, among predominantly matrilineal women in a rural setting in Ghana.

\section{Methods}

It was a cross-sectional study conducted between 2nd January and 30th April 2012 at four health facilities in the Mfantseman Municipality (predominantly rural in nature) of the Central Region of Ghana, namely the Saltpond Municipal Hospital, Mankessim Health Centre (both primary level and semi-urban) and the Biriwa and Anomabo Health Centers (both primary level and rural). These health facilities were selected out of seven public health facilities because they were the main facilities in the municipality that carried out almost all the reproductive, child health and nutrition activities, had relatively high numbers of antenatal visits and deliveries [13], and also gave a good mix of semi-urban and rural settings. Using total enumerative sampling technique, all pregnant Ghanaian women, aged 15-49 years, living in the municipality and attending antenatal clinic at any of the selected health facilities at designated antenatal times, were selected for interview within the premises of the health facilities using a five-page questionnaire. Questionnaire administration was carried out by trained field assistants and supervisors mainly from the Mfantseman Municipal Health Directorate.

The questionnaire was constructed using information mainly from questionnaires of the Ghana Demographic and Health Survey 2008. Review of the questionnaire was carried out with support of the Mfantseman Municipal Director of Health Services, Medical Superintendent of the Saltpond Municipal Hospital, the Director of Family Health Division, Ghana Health Service and Academic Senior members of the University of Cape Coast. Questions related to both explanatory and outcome variables were asked. Those related to explanatory variables included socio-demographic characteristics of respondents, the number of living children and sex of the children, 
issues pertaining to the nature of relationship between respondents and their male partners and awareness and ever use of various family planning methods. Those related to the outcome variables included respondents' reproductive history, including the assessment of the current pregnancy as intended or unintended, and the intention to adopt postpartum family planning (PPFP).

Based on an estimated target population $\left(\mathrm{N}_{\mathrm{f}}\right)$ of 4218 (an average number of women attending antenatal clinics per quarter from 2007 to 2010 in the municipality) [13], and the assumption that $50 \%$ of pregnant women intended to adopt postpartum family planning, within a margin of error of $3 \%$, a minimum sample size $\mathrm{S}_{\mathrm{f}}$, was estimated as follows: For a finite population, the sample size $S_{f}$, was estimated by the formula $S_{f}=A$ / [1 $\left.+(A-1) / N_{f}\right][14]$, where A is given by $\left[Z^{*} P^{*}(1-P)\right] / C^{2}$; $\mathrm{N}_{\mathrm{f}}=$ estimated target population; $\mathrm{Z}=\mathrm{Z}$ value (1.96 for 95\% confidence); $\mathrm{P}=$ proportion of pregnant women who intended to adopt postpartum family planning; and $\mathrm{C}=$ margin of error $[15] . \quad \mathrm{A}=\left[1.96^{2}(0.5)(0.5)\right] / 0.03^{2}=$ $1067 ; \quad S_{\mathrm{f}}=1067 /[1+(1067-1) / 4218]=852$; $\quad$ (approximated to 900). For effective antenatal care and early identification and management of complications, it was important and advisable for all women to report to antenatal clinic as soon as they noticed they were pregnant [13]; implying that all pregnant women were assumed to have registered in the first trimester of pregnancy. Evidence from the Ghana Health Service, Central Regional Family Health Report, 2011, showed that this was not the case: only $43 \%$ registered in their first trimester, whilst the remainder registered in the second or third trimester [13]. It was also recommended that all antenatal registrants delivered at the health facilities at term to ensure adequate supervision during delivery by skilled personnel. However, the same report showed that only $44 \%$ of them delivered at the health institutions within the municipal area [13]. This implied a default rate of close to $60 \%$. To take care of defaults and late registrations, the minimum sample size $\left(S_{\mathrm{f}}=900\right)$ computed was doubled to 1800 with an additional 10\% mark-up for women who declined to be interviewed. The estimated total sample size $S_{\mathrm{T}}$ was 1980 .

It was estimated from municipal records [13] that the ratio of average antenatal visits in the municipal hospital to those of a health centre was 3:1. Therefore, the estimated sample size for each health centre is given by $S_{h}=S_{m} / 3$; but the computed sample size for the Saltpond municipal hospital was approximately 990; implying that of each health centre is approximately 330 . The total estimated sample size $\left(\mathrm{S}_{\mathrm{T}}\right)$ is given by $\mathrm{S}_{\mathrm{T}}=\mathrm{Sm}+3 \mathrm{Sh}=1980$. Within the period of the study, 1914 pregnant women were interviewed with distribution as follows: Saltpond municipal hospital $=968$ (response rate, RR-97.8\%); Mankessim health centre $=289$ (RR-87.6\%); Anomabo health centre $=327$
(RR-99.1\%); Biriwa health centre $=330($ RR-100\%). Disparities in response rates occurred because some qualified clients declined interview for socio-cultural, religious and personal reasons. For the purposes of this study however, women with living children at the time of the survey and whose socio-demographic data were complete (1091) were recruited from the total sample of 1914 and characterized using total number and sex of children. Figure 1 shows a flow diagram of the selection process. At the end of each interview, field assistants and/or supervisors checked the questionnaires for completeness and consistency before the clients were allowed to leave.

Each of the selected health facilities was assigned a peculiar code to allow for easy identification and tracking if errors and inconsistencies were detected. For data entry, a coding manual was developed in order to ensure consistency. The data were double-entered using the EPI-DATA and verified. The cleaned data were exported into STATA/IC (version 11.2) for analysis.

The main outcomes of interest in this study were "unintended pregnancy" and "intention to adopt family planning postpartum". Each of the outcome variables was constructed as a binary outcome and defined as follows: unintended pregnancy (denoted as ' 1 ') - any pregnancy that was unwanted (i.e. that occurred when no children, or no more children were desired) or mistimed (i.e. that occurred earlier than desired). An intended pregnancy (denoted as ' 0 ') was defined as any pregnancy that was wanted at the time it occurred; intention to adopt contraceptives postpartum is defined as intending to adopt a family planning method in order to avoid getting pregnant too soon after delivery; ' 1 ' denoting intention to adopt and ' 0 ' denoting intention not to adopt postpartum family planning.

The key explanatory variable of interest in this study was sex composition of children. This was based on the sex and number of living children. Sex composition of children was categorized into five groups as follows: (a) only daughters; (b) only sons; (c) more daughters than sons; (d) more sons than daughters; and (e) equal numbers of daughters and sons. In addition, some key demographic characteristics considered in the analysis included age, marital status, education, parity, gravidity, religion, occupation and area of residence.

Descriptive analyses of the explanatory variables were conducted using simple proportions, means and standard deviations. Chi square statistics was used to explore the association between explanatory variables (sex composition and key socio-demographic characteristics) and the outcome variables (unintended pregnancy and intended PPFP use). A significant association was said to exist if $P<0.05$. This significance level was selected based on its application in previous studies and because it provides a fair chance 


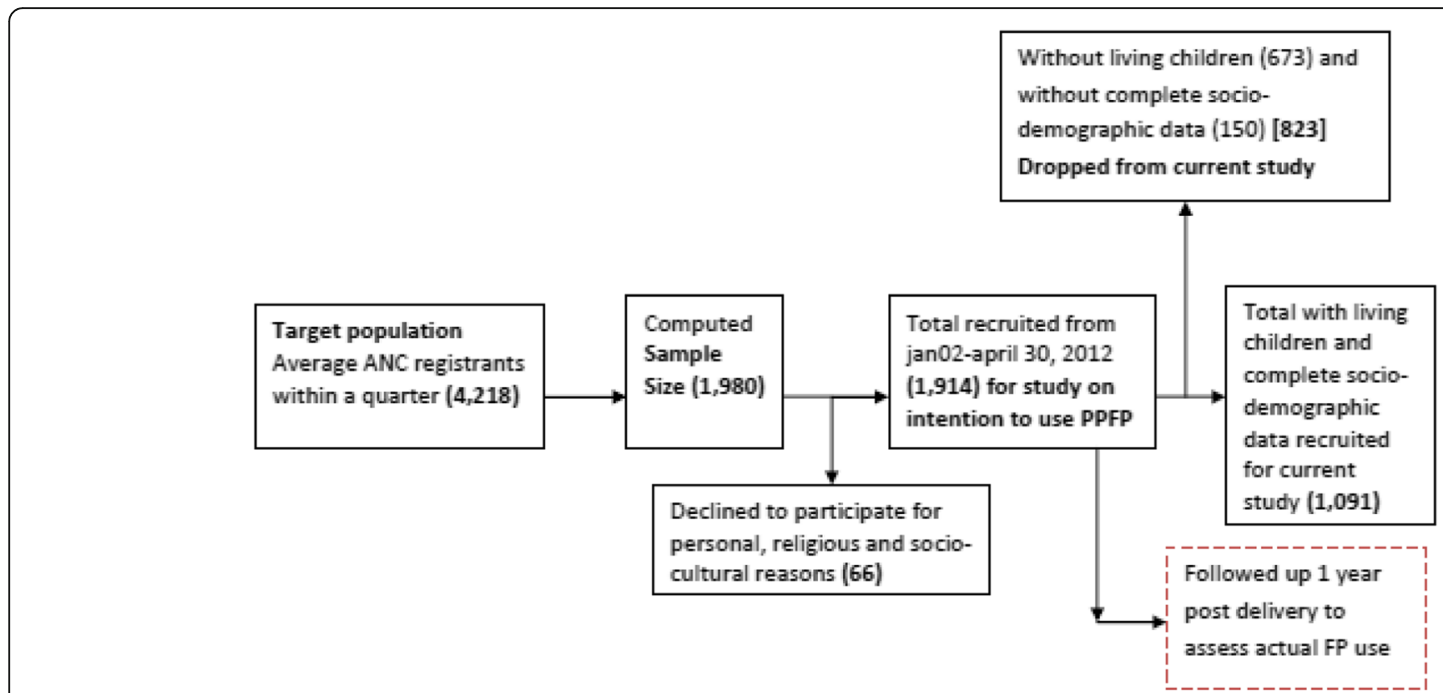

Fig. 1 Flow diagram showing how participants were recruited for current studySource: Field work 2014

of picking up those effects which are large enough to be of scientific interest.

Controlling for key socio-demographic characteristics, a multivariate logistic regression analyses was conducted to determine if sex composition was independently associated with pregnancy intendedness and intention to use postpartum family planning. Strength of association was determined by computing odds ratios and confidence intervals. Significance levels were determined at $P<0.05$.

Ethical approval was obtained from the Ethics Review Committee of the Ghana Health Service (GHS) (GHS-ERC: 14/09/11). Institutional approval was also obtained from the Municipal Health Directorate (MHD) and the heads of the facilities where the surveys were conducted. Written informed consent was obtained from each participant before the administration of questionnaires.

\section{Results}

\section{Descriptive analysis}

The mean age of the 1091 respondents interviewed in this study was $28.2 \pm 6.0$ years, with majority of them (30.1\%) aged 25-29 years (Table 1 ). The mean gestational age was $26.7 \pm 6.6$ weeks. The average number of children per woman was $2.0 \pm 1.0$ and sex ratio of 109 males to100 females (consisting of 861 males and 792 females). The women who had only sons constituted $28.7 \%$ whilst $22.4 \%$ had only daughters. Of those who had sons and daughters, $13.8 \%$ had more daughters than sons, $15 \%$ had more sons than daughters and $20.1 \%$ had equal number of sons and daughters (Table 1). This implies that respondents who had at least a son and a daughter constituted $78 \%$ and $71 \%$ respectively. Those who had only sons exceeded those with only daughters by $6.3 \%$.
Characteristics of women and their association with unintended pregnancy and intention to use postpartum family planning

Unintended pregnancies were generally high among the women (70\%). An association existed between unintended pregnancy and sex composition of children $\left(\mathrm{X}^{2}=42.0, P<0.001\right)$; educational status $\left(\mathrm{X}^{2}=19.2, P\right.$ $<0.01)$; parity $\left(\mathrm{X}^{2}=33.4, P<0.001\right)$; place of residence $\left(\mathrm{X}^{2}=13.1, \quad P<0.05\right)$, occupation $\left(\mathrm{X}^{2}=32.3, \mathrm{P}<0.001\right)$ and marital status $\left(\mathrm{X}^{2}=21.6, P<0.001\right)$ [Table 1]. The highest levels of unintended pregnancy were among women with: more sons than daughters (84.1\%); no education (75.4\%); parity five or more (89\%); residence at Anomabo; farming as occupation (80\%); and single women $(81.8 \%)$ [Table1].

Similarly, a high percentage of women (78\%) expressed intention to use postpartum family planning. An association existed between women with intention to use postpartum family planning and educational status $\left(X^{2}=20.3, P<0.001\right)$, place of residence $\left(X^{2}\right.$ = 26.2, $\mathrm{P}<0.001)$; occupation $\left(\mathrm{X}^{2}=17.1, P<0.01\right)$ and marital status $\left(X^{2}=21.0, P<0.001\right)$. There was however, no association between intention to use postpartum family planning and sex composition of children. The women with primary education, resident in Anomabo, farmers and those cohabiting, expressed the highest levels of intention to use postpartum family planning (Table 1).

\section{Multivariate logistic regression analyses of sex composition on unintended pregnancy and intention to use postpartum family planning}

Controlling for socio-demographic characteristics, women with only sons were less likely to classify their pregnancy as unintended compared to those with equal 
Table 1 Characteristics of participants and their association with unintended pregnancy and intention to use postpartum family planning (PPFP)

\begin{tabular}{|c|c|c|c|c|}
\hline & Sample & & Unintended Pregnancy & Intention to use PPFP \\
\hline Characteristic & N & $\%$ & $\%$ & $\%$ \\
\hline \multicolumn{5}{|l|}{ Sex Composition } \\
\hline Only daughters & 244 & 22.4 & 65.2 & 77.9 \\
\hline Only sons & 313 & 28.7 & 58.8 & 75.4 \\
\hline More daughters than sons & 151 & 13.8 & 78.1 & 83.4 \\
\hline More sons than daughters & 164 & 15.0 & 84.1 & 78.0 \\
\hline Equal number of sons and daughters & 219 & 20.1 & 72.6 & 77.2 \\
\hline$X^{2}(P$ value $)$ & - & - & $42.0(0.000)$ & $3.9(0.421)$ \\
\hline \multicolumn{5}{|l|}{ Age } \\
\hline $15-19$ & 36 & 3.3 & 80.6 & 72.2 \\
\hline $20-24$ & 293 & 26.9 & 68.9 & 78.8 \\
\hline $25-29$ & 328 & 30.1 & 70.1 & 78.7 \\
\hline $30-34$ & 237 & 21.7 & 63.7 & 77.2 \\
\hline $35-39$ & 146 & 13.4 & 71.9 & 75.3 \\
\hline $45+$ & 51 & 4.7 & 80.4 & 80.4 \\
\hline$X^{2}(P$ value $)$ & - & - & $9.2(0.102)$ & $1.7(0.885)$ \\
\hline \multicolumn{5}{|l|}{ Educational level } \\
\hline No education & 289 & 26.5 & 75.4 & 78.2 \\
\hline Primary & 268 & 24.6 & 71.3 & 82.5 \\
\hline Middle/JSS & 447 & 41.0 & 68.0 & 78.3 \\
\hline SSS/SHS/Nocational & 65 & 6.0 & 53.8 & 61.5 \\
\hline Tertiary & 22 & 2.0 & 45.5 & 54.5 \\
\hline$X^{2}(P$ value $)$ & - & - & $19.2(0.001)$ & $20.3(0.000)$ \\
\hline \multicolumn{5}{|l|}{ Religion } \\
\hline Christian & 1009 & 92.5 & 69.8 & 78.2 \\
\hline Muslim & 53 & 4.9 & 60.4 & 67.9 \\
\hline Others & 29 & 2.7 & 75.9 & 82.8 \\
\hline$X^{2}(P$ value $)$ & - & - & $2.7(0.263)$ & $3.5(0.174)$ \\
\hline \multicolumn{5}{|l|}{ Parity } \\
\hline $1-2$ & 684 & 62.7 & 63.9 & 76.3 \\
\hline $3-4$ & 307 & 28.1 & 75.6 & 79.8 \\
\hline $5+$ & 100 & 9.2 & 89.0 & 82.0 \\
\hline$X^{2}(P$ value $)$ & - & - & $33.4(0.000)$ & $2.6(0.271)$ \\
\hline \multicolumn{5}{|l|}{ Residence } \\
\hline Saltpond & 259 & 23.7 & 64.5 & 80.3 \\
\hline Biriwa & 132 & 12.1 & 75.8 & 78.0 \\
\hline Anomabo & 187 & 17.1 & 77.5 & 88.8 \\
\hline Mankessim & 305 & 28.0 & 65.9 & 69.5 \\
\hline Others & 208 & 19.1 & 69.7 & 76.9 \\
\hline$X^{2}(P$ value $)$ & - & - & $13.1(0.011)$ & $26.2(0.000)$ \\
\hline
\end{tabular}


number of sons and daughters (AOR 0.5, 95\% CI $0.3-$ 0.8) (Table 2).

Women with five or more living children were more likely than those with 1 to 2 living children to classify their current pregnancy as unintended (AOR 3.8, 95\% CI1.7-8.6). Likewise, women living in rural settings like Anomabo (AOR 1.8, 95\% CI 1.1-2.8) and younger women $(<20$ years) respectively, were more likely to report unintended pregnancies compared to those living in semi-urban settings (Saltpond) and older women (> 30 years) (Table 2). No significant association existed between respondents sex composition and intention to use postpartum family planning, however, whilst women resident in Anomabo were more likely to have intention to use postpartum family planning (AOR 1.8, 95\% CI1.0-3.3), those from Mankessim were less likely to have intention to use postpartum family planning (AOR 0.6, 95\% CI 0.4-0.9), compared to those from Saltpond respectively (Table 3 ).

\section{Discussion}

Strong gender preference often stems from the requirements of lineage. Matrilineal and matrilocal societies may prefer couples to have more daughters, whilst strong patrilineal and patrilocal societies may prefer couples have more boys [16]. There is however a large body of evidence indicating that both sons and daughters are desired [3].The reported sex composition of living children was skewed towards males in this study. While $78 \%$ of the women had at least a son, $71 \%$ had at least a daughter with those having only sons exceeding those with only daughters by $6.3 \%$. Also, a high proportion of women with more sons than daughters reported that their current pregnancies were unintended. These observations coupled with a sex ratio of 109:100 may infer that although both sexes are desired, some underlying son preference persisted.

The communities that the women are resident in (Anomabo, Biriwa, and Saltpond) are predominantly coastal in nature, with fishing as the main livelihood. Because the fishing industry is male dominated, with a high demand for males, sons may be preferred to ensure continuity of the business. Further investigations may be required to consolidate this fact. The inferred underlying son preference in this typical matrilineal system is consistent with findings in previous studies conducted in sub-Saharan Africa and other countries where male preference had been widely reported $[14,17,18]$ and contrasts studies in Malawi and tribal societies of Meghalaya, India where preference for daughters was the norm in predominantly matrilineal areas $[19,20]$.

The highest proportion of unintended pregnancy was found among women with more sons than daughters. This implies that majority of women in this category did
Table 2 Multivariate logistic regression of sex composition and unintended pregnancy

\begin{tabular}{|c|c|c|c|}
\hline Characteristic & OR & $95 \% \mathrm{Cl}$ & $P$-Value \\
\hline Sex Composition & $1.1^{*}$ & {$[1.0,1.2]$} & 0.013 \\
\hline \multicolumn{4}{|c|}{ Equal number of sons and daughters (REF) } \\
\hline Only daughters & 0.7 & {$[0.5,1.1]$} & 0.098 \\
\hline Only sons & $0.5^{* *}$ & {$[0.4,0.8]$} & 0.001 \\
\hline More daughters than sons & 1.1 & {$[0.6,2.0]$} & 0.756 \\
\hline More sons than daughters & 1.6 & {$[0.9,2.8]$} & 0.128 \\
\hline Age & $0.8^{* *}$ & {$[0.7,0.9]$} & 0.000 \\
\hline \multicolumn{4}{|l|}{ 15-19 (REF) } \\
\hline $20-24$ & 0.5 & {$[0.2,1.3]$} & 0.177 \\
\hline $25-29$ & 0.5 & {$[0.2,1.3]$} & 0.156 \\
\hline $30-34$ & $0.2^{* *}$ & {$[0.1,0.6]$} & 0.003 \\
\hline $35-39$ & $0.3^{*}$ & {$[0.1,0.7]$} & 0.010 \\
\hline $40+$ & $0.3^{*}$ & {$[0.1,0.9]$} & 0.027 \\
\hline Educational level & 1.0 & {$[0.8,1.1]$} & 0.625 \\
\hline \multicolumn{4}{|l|}{ No education (REF) } \\
\hline Primary & 1.0 & {$[0.7,1.5]$} & 0.885 \\
\hline Middle/JSS & 1.2 & {$[0.8,1.7]$} & 0.442 \\
\hline SSS/SHS/Nocational & 0.9 & {$[0.5,1.7]$} & 0.678 \\
\hline Tertiary & 1.1 & {$[0.3,3.5]$} & 0.909 \\
\hline Religion & 1.0 & {$[0.7,1.4]$} & 0.933 \\
\hline \multicolumn{4}{|l|}{ Christian (REF) } \\
\hline Muslim & 0.7 & {$[0.4,1.4]$} & 0.368 \\
\hline Others & 1.3 & {$[0.6,3.2]$} & 0.519 \\
\hline Parity & $2.2^{* *}$ & {$[1.6,3.0]$} & 0.000 \\
\hline \multicolumn{4}{|l|}{$1-2$ (REF) } \\
\hline $3-4$ & 1.4 & {$[0.9,2.3]$} & 0.120 \\
\hline $5+$ & $3.8^{* *}$ & {$[1.7,8.6]$} & 0.001 \\
\hline Residence & 1.1 & {$[1.0,1.2]$} & 0.306 \\
\hline \multicolumn{4}{|l|}{ Saltpond (REF) } \\
\hline Biriwa & 1.4 & {$[0.8,2.3]$} & 0.243 \\
\hline Anomabo & $1.8^{*}$ & {$[1.1,2.8]$} & 0.017 \\
\hline Mankessim & 1.2 & {$[0.8,1.8]$} & 0.377 \\
\hline Others & 1.3 & {$[0.9,1.9]$} & 0.244 \\
\hline Occupation & $0.9^{*}$ & {$[0.8,1.0]$} & 0.036 \\
\hline \multicolumn{4}{|l|}{ Fishmongers (REF) } \\
\hline Farmers & 1.2 & {$[0.6,2.7]$} & 0.608 \\
\hline Petty traders & 0.9 & {$[0.6,1.4]$} & 0.767 \\
\hline Civil/public servants & 0.5 & {$[0.2,1.2]$} & 0.128 \\
\hline Others & 0.7 & {$[0.4,1,2]$} & 0.160 \\
\hline Marital Status & 1.1 & {$[1.0,1.3]$} & 0.128 \\
\hline \multicolumn{4}{|l|}{ Ordinace (REF) } \\
\hline Traditional & 1.0 & {$[0.7,1.7]$} & 0.847 \\
\hline Engaged & 0.7 & {$[0.4,1.2]$} & 0.217 \\
\hline Cohabiting & 1.1 & {$[0.6,2.0]$} & 0.729 \\
\hline Single & 2.2 & {$[0.8,5.9]$} & 0.118 \\
\hline
\end{tabular}

REF Reference Category; ${ }^{*} p<.05,{ }^{* *} p<.01 ; 95 \%$ confidence intervals in brackets 
not want the pregnancy at the time it occurred or did not want it at all. The reasons may be that, they had satisfied the number and composition of their children. These findings are consistent with other studies in South Asia where women with more sons were less likely to want more children, and therefore any pregnancy that occurred may be unintended $[3,5,6]$. Unintended pregnancies, especially in sub-Saharan Africa, invariably end up in unsafe abortions whose associated health consequences and burdens disproportionately affect women. In many countries in sub-Saharan Africa, women's access to safe abortion and post-abortion care for complications is hampered by restrictive laws, socio-cultural barriers, and inadequate resources to provide safe abortion [21]. These need to be addressed in order to prevent women from dying from unintended pregnancies.

In this study, women with only sons were significantly less likely to be carrying unintended pregnancies at the time of the survey. This implied that these women intended the pregnancies they were carrying. A similar finding was made by Calhoun and colleagues where families with only sons were significantly more likely to want more children and therefore any additional pregnancy may be intended [3]. For the women with only sons, any additional pregnancy may be intended to satisfy the sex composition of their children and to ensure continuity of the matrilineal inheritance system. This may be consistent with studies that showed that both girls and boys are valued in a system which is matrilineal but has patriarchal elements $[3,5]$.

This study also revealed that sex composition of children is not significantly associated with intention to use postpartumn contraceptives. This is not surprising because globally, research on the association between family sex composition and fertility behaviours such as fertility desires, intentions to use family planning and actual family planning use is not conclusive [3]. Intention to use postpartum family planning in this study was however influenced by residence in rural settings likeAnomabo because they reported the most unintended pregnancies compared to those resident in semi-urban settings like Saltpond.

\section{Strengths and limitations of study}

The cross-sectional design was appropriate for the study considering the time constraints imposed by the limited funding. The fact that the respondents were selected from health facilities may affect the generalizability of the findings. The threat of selection bias was highly mitigated by ensuring that the data collectors explained the study objectives and their implications very well to the respondents before asking for consent. Some of the data collectors abandoned the study because of inadequate remuneration. New data collectors had to be trained to
Table 3 Multivariate logistic regression of sex composition and intention to use PPFP

\begin{tabular}{|c|c|c|c|}
\hline Characteristic & OR & $95 \% \mathrm{Cl}$ & $P$-value \\
\hline Sex Composition & 1.0 & {$[1.0,1.1]$} & 0.651 \\
\hline \multicolumn{4}{|c|}{ Equal number of sons and daughters (REF) } \\
\hline Only daughters & 1.1 & {$[0.7,1.8]$} & 0.582 \\
\hline Only sons & 1.0 & {$[0.6,1.6]$} & 0.979 \\
\hline More daughters than sons & 1.3 & {$[0.7,2.5]$} & 0.411 \\
\hline More sons than daughters & 1.0 & {$[0.5,1.8]$} & 0.909 \\
\hline Age & 1.0 & {$[0.8,1.1]$} & 0.555 \\
\hline \multicolumn{4}{|l|}{ 15-19 (REF) } \\
\hline $20-24$ & 1.7 & {$[0.8,4.0]$} & 0.200 \\
\hline $25-29$ & 1.9 & {$[0.8,4.7]$} & 0.118 \\
\hline $30-34$ & 1.6 & {$[0.7,3.9]$} & 0.308 \\
\hline $35-39$ & 1.3 & {$[0.5,3.3]$} & 0.614 \\
\hline $45+$ & 1.6 & {$[0.5,5.3]$} & 0.473 \\
\hline Educational level & 0.9 & {$[0.8,1.1]$} & 0.271 \\
\hline \multicolumn{4}{|l|}{ No education (REF) } \\
\hline Primary & 1.6 & {$[1.0,2.5]$} & 0.051 \\
\hline Middle/JSS & 1.4 & {$[0.9,2.0]$} & 0.153 \\
\hline SSS/SHS/Nocational & 0.8 & {$[0.4,1.5]$} & 0.423 \\
\hline Tertiary & 0.6 & {$[0.2,2.1]$} & 0.460 \\
\hline Religion & 0.9 & {$[0.6,1.2]$} & 0.505 \\
\hline \multicolumn{4}{|l|}{ Christian (REF) } \\
\hline Muslim & 0.8 & {$[0.4,1.6]$} & 0.538 \\
\hline Others & 1.0 & {$[0.4,2.8]$} & 0.951 \\
\hline Parity & 1.2 & {$[0.9,1.6]$} & 0.308 \\
\hline \multicolumn{4}{|l|}{$1-2$ (REF) } \\
\hline $3-4$ & 1.1 & {$[0.6,1.8]$} & 0.799 \\
\hline $5+$ & 1.3 & {$[0.6,3.1]$} & 0.482 \\
\hline Residence & 0.9 & {$[0.8,1.0]$} & 0.109 \\
\hline \multicolumn{4}{|l|}{ Saltpond (REF) } \\
\hline Biriwa & 0.7 & {$[0.4,1.3]$} & 0.255 \\
\hline Anomabo & $1.8^{*}$ & {$[1.0,3.3]$} & 0.035 \\
\hline Mankessim & $0.6^{*}$ & {$[0.4,0.9]$} & 0.015 \\
\hline Others & 0.8 & {$[0.5,1.2]$} & 0.297 \\
\hline Occupation & 0.9 & {$[0.8,1.0]$} & 0.072 \\
\hline \multicolumn{4}{|l|}{ Fishmongers (REF) } \\
\hline Farmers & 1.1 & {$[0.5,2.5]$} & 0.742 \\
\hline Petty traders & 1.1 & {$[0.7,1.7]$} & 0.829 \\
\hline Civil/public servants & 0.7 & {$[0.3,2.0]$} & 0.527 \\
\hline Others & 0.7 & {$[0.4,1.2]$} & 0.217 \\
\hline Marital Status & 1.1 & {$[0.9,1.3]$} & 0.314 \\
\hline \multicolumn{4}{|l|}{ Ordinace (REF) } \\
\hline Traditional & 1.4 & {$[0.9,2.4]$} & 0.145 \\
\hline Engaged & 0.9 & {$[0.5,1.7]$} & 0.804 \\
\hline Cohabiting & 1.4 & {$[0.7,2.6]$} & 0.323 \\
\hline Single & 1.0 & {$[0.4,2.7]$} & 0.999 \\
\hline
\end{tabular}

REF Reference Category; * $p<.05,{ }^{* *} p<.01 ; 95 \%$ confidence intervals in brackets 
continue data collection. This brought about some delays in data analysis and reporting.

\section{Conclusions}

The purpose of the study was to explore the existence of sex preference in a matrilineal inheritance system by examining the sex composition of living children and how it is associated with reproductive or fertility outcomes such as pregnancy intendedness and intention to use postpartum family planning. The persistence of more sons than daughters, high sex ratio and the high prevalence of unintended pregnancy among women with more sons than daughters, inferred son preference in a matrilineal inheritance system. Among the women with only sons, any additional pregnancy was intended to satisfy the sex composition of their children in order to consolidate and ensure continuity of the matrilineal inheritance system. Furthermore, sex composition of children was significantly associated with pregnancy intendedness and not postpartum family planning intentions. Women with more sons than daughters may have the highest unmet need for family planning. Postpartum family planning programming will require deeper understanding of the traditional and family contexts in which programmes are launched in order to ensure effective targeting.

\section{Acknowledgements}

We wish to acknowledge the cooperation of pregnant women in all four health facilities where the study was conducted. We also wish to recognize the work of the interviewers in the respective facilities, the heads and staff of the facilities who supported the conduct of the study in diverse ways. We are particularly grateful to the Mfantseman Municipal Health Directorate and the management of the Saltpond Municipal Hospital for allowing the study to be undertaken in their facilities.

\section{Consent to participate}

Before each interview, the aims, objectives and benefits of the study were explained to respondents; they were then allowed to ask any questions for clarifications. Once they consented, they were made to sign with a witness of their choice. Interviews were conducted in places that guaranteed maximum privacy. For individuals who could have emotional problems from interviews, the research assistants were taught to reassure clients and immediately report to the Principal Investigator (who is a Physician) to manage those concerned. A Clinical Psychologist from the School of Medical Sciences, University of Cape Coast was recruited on stand-by to handle cases that were beyond the control of the Principal Investigator.

\section{Funding}

Funding for this study was self.

\section{Availability of data and materials}

The data that supports the study has individual identifiers and researcher is reserved to provide it. Parts of data are provided in the Tables 1, 2 and 3.

\section{Consent to publish}

As part of the ethical process to obtain consent for participation in the study, consent was obtained from all the participants to publish information obtained from them but without the personal identifiers. These were also witnessed accordingly.

\section{Authors' contributions}

SE and FB were responsible for the conceptualization of the study. SE and FB were responsible for its design and implementation.SE and DA were responsible for cleaning the data and carrying out the statistical analysis. SE and was responsible for production of the initial draft of the manuscript. SE was responsible for finalizing the manuscript after critical review by KAA. All authors read and approved the final manuscript.

\section{Authors' information}

SE is a Public Health Physician and Seniour Lecturer in the Department of Community Medicine, University of Cape Coast, Ghana; FB is a Public Health Physician and Seniour Researcher at Centre for health Research and Implementation Support; DA is a Lecturer at Department of Community Medicine School of Medical Sciences, University of Cape Coast; KAA is a Professor in Population and Health at the Faculty of Social Science, University of Cape Coast, Ghana.

\section{Ethics approval}

Ethical and administrative approvals were obtained from the Ethics Review Committee of the Ghana Health Service and the Municipal Health Directorate (GHS-ERC: 14/09/11). Written informed consent was obtained from each participant and witnessed.

\section{Competing interests}

The authors declare no conflict of interest.

\section{Publisher's Note}

Springer Nature remains neutral with regard to jurisdictional claims in published maps and institutional affiliations.

\section{Author details}

${ }^{1}$ Department of Community Medicine, University of Cape Coast, Cape Coast, Ghana. ${ }^{2}$ Centre for Health Research and Implementation Support, Accra, Ghana. ${ }^{3}$ Department of Community Medicine, School of Medical Sciences, University of Cape Coast, Cape Coast, Ghana. ${ }^{4}$ Department of Population and Health, University of Cape Coast, Cape Coast, Ghana.

Received: 23 October 2017 Accepted: 30 September 2018

Published online: 09 November 2018

References

1. Qian N. Missing women and the Price of tea in China: the effect of sexspecific earnings on sex imbalance. Q J Econ. 2008;123(3):1251-85.

2. Preventing gender-biased sex selection: an interagency statement $\mathrm{OHCHR}$, UNFPA, UNICEF, UN Women and WHO. https://www.unfpa.org/sites/default/ files/resource-pdf/Preventing_gender-biased_sex_selection.pd.

3. Calhoun LM, Nanda P, Speizer IS, Meenakshi J. The effect of family sex composition on fertility desires and family planning behaviors in urban Uttar Pradesh, India. Reprod Health. 2013;10:48.

4. Chaudhuri S. The desire for sons and excess fertility: a household analysis of parity progression in India. Int Perspect Sex Reprod Health. 2012:38(4):78-186.

5. Edmeades J, Pande R, Macquarrie K, Falle T, Malhotra A. Two sons and a daughter: sex composition and women's reproductive behaviour in Madhya Pradesh, India. J Biosoc Sci. 2012;44:749-64.

6. Jayaraman A, Mishra V, Arnold F. The relationship of family size and composition to fertility desires, contraceptive adoption and method choice in South Asia. International Perspectives in Sexual and Reproductive Health. 2009:3:29-38.

7. Fuse K.: Variations in attitudinal gender preferences for children across 50 less-developed countries. Demogr Res 2010; Vol.23, Article 36. https://www. demographic-research.org/volumes/vol23/36/23-36.pdf.

8. Millazo A. Son preference, fertility and family structure: evidence from reproductive behavior among Nigerian women. Job market paper. 2012. http://hdl.handle.net/10986/18805.

9. Ghana Statistical Service. Population and housing census: National Analytical Report. Accra, Ghana Statistical Service. 2010;2013.

10. Nukunya GK. Tradition and change in Ghana: an introduction to sociology. Accra: Ghana Universities Press; 2003. (2nd Ed.)

11. Kpoor A. The nuclearization of Ghanaian families. Current politics and economics of Africa. 2015;8(3).

12. Awusabo-Asare K. Matriliny and the New Intestate Succession Law of Ghana. Canadian Journal of African Studies. 1990;24(1):1-14.

13. Ghana Health Service, Central Region, Reproductive and Child Health Reports 2008-2010. 
14. Ndu AC, Uzochukwu BSU. Child gender preferences in an urban and rural community in Enugu, eastern Nigeria. Journal of College of Medicine. 2011;16(1).

15. Creative Research Systems: The survey system- Sample size formulas. 2012. www.surveysystem.com/sample-size-calculator.htm

16. Rossi P, Rouanet L. Gender Preferences in Africa: A Comparative Analysis of Fertility Choices. Paris School of Economics. Working paper n. 2014:33.

17. Adeleye OA, Okonkwo CA. Ideal Child Gender Preference in Men's Worldview and Their Knowledge of Related Maternal Mortality Indices in Ekiadolor, Southern Nigeria. Asian Journal of Medical Sciences. 2010;2(3):146-51.

18. Rossi P, Rouanet L. Gender preferences in Africa: a comparative analysis of fertility choices. PSE Working Papers n² 2014-33. 2015.

19. Adebowale SA, Palamuleni ME. Influence of gender preference and sex composition of surviving children on childbearing intention among high fertility married women in stable union in Malawi. Africa Health Science. 2015:15(1):150-60.

20. Narzary PK, Sharma SM. Daughter preference and contraceptive-use in matrilineal tribal societies in Meghalaya, India. Journal of Health Population and Nutrition. 2013 Jun;31(2):278-89.

21. Rominski SD, Review JR. Abortion care in Ghana: a critical review of the literature. Afr J Reprod Health. 2014;18(3):17-35.

Ready to submit your research? Choose BMC and benefit from:

- fast, convenient online submission

- thorough peer review by experienced researchers in your field

- rapid publication on acceptance

- support for research data, including large and complex data types

- gold Open Access which fosters wider collaboration and increased citations

- maximum visibility for your research: over $100 \mathrm{M}$ website views per year

At $\mathrm{BMC}$, research is always in progress.

Learn more biomedcentral.com/submissions 